\title{
Cultura do trabalho, autogestão e formação de trabalhadores associados na produção: questões de pesquisa
}

\author{
Lia Tiriba*
}

\section{Resumo:}

Partimos do pressuposto de que os conceitos são produtos das condições históricas de um determinado espaço/tempo, carregando consigo algo que é e, ao mesmo tempo, pode vir a ser. Em busca de subsídios teórico-metodológicos que contribuam para refletir sobre as dimensões educativas dos processos de trabalho sob o controle dos trabalhadores, (re) visitamos - à luz do materialismo histórico - as categorias "produção associada", "autogestão" e "cultura do trabalho", fazendo referência a diferentes contextos em que os trabalhadores tomaram para si os meios de produção. Problematizamos os processos de formação de trabalhadores associados, tendo em conta o movimento social por uma economia popular solidária que, desde o final da década de 1980, com a crise estrutural do emprego, se constrói em âmbito latino-americano.

Palavras-chave: Trabalhadores-Formação. Trabalho.

\footnotetext{
* Doutora em Ciências Políticas e Sociologia pela Universidade Complutense de Madrid (Programa Sociologia Econômica e do Trabalho). Professora da Faculdade de Educação da Universidade Federal Fluminense (UFF). Pesquisadora do Núcleo de Estudos, Documentação e Dados sobre Trabalho e Educação, NEDDATE/ UFF.
} 
Em diversos momentos da história do capitalismo, os trabalhadores tomaram para si os meios de produção, organizando - eles mesmos - o processo de trabalho. Como estratégia de sobrevivência ou estratégia de ruptura com as relações capitalistas de produção, como um paliativo à crise estrutural do capital ou como uma instância dos processos mais amplos de construção de uma nova sociedade, os trabalhadores associados têm tentado, à sua maneira, "governar" a si mesmos e/ou o mundo do trabalho. Nos diferentes espaços e tempos históricos, como aqueles que foram expulsos ou mesmo nunca ingressaram no mercado (capitalista) de trabalho otganizam a produção? Como concebem as relações de convivência? No processo de produzir a vida social, como se dão as relações entre trabalho e educação? O que entendem por autogestão? Que concepções de trabalho e de sociedade fundamentam seus projetos educativos? Quais os nexos entre processo de trabalho, processo educativo e projeto societário? Em que medida o cotidiano da produção associada reproduz uma cultura do trabalho inspirada na organização capitalista do trabalho?

Instigados por esta e outras questões de pesquisa', partimos do pressuposto de que os conceitos de "produção associada", "autogestão" $e$ "cultura do trabalho" são produtos das condições históticas de um determinado espaço/tempo, carregando consigo algo que é e, ao mesmo tempo, pode vir a ser. Neste sentido, organizamos este artigo em quatro partes que se articulam no sentido de buscat subsídios teórico-metodológicos para refletir sobre as dimensões educativas dos processos de trabalho sob o controle dos trabalhadores. Na primeira, indicamos que, como elemento de produção da vida social, o processo de trabalho é, em si, educativo. Ressaltamos que, ao longo da história, como estratégia de sobrevivência e/ ou de produção de uma nova sociedade, uma parcela da classe trabalhadora tem vivido experiências associativas que se constituem como "escolas" de produção de uma cultura do trabalho e que, de alguma maneira, contrariam a lógica excludente do sistema capitalista. $\mathrm{Na}$ segunda parte, contextualizamos os atuais movimentos de trabalhadores associados, considerando que a crise do paradigma keynesiano, que pressupõe a ação protetora do Estado a todos os cidadãos, levou às últimas conseqüências a marginalização e a exclusão da população do direito ao trabalho, saúde, educação e previdência social. Na terceira parte, (re)visitamos - à luz do materialismo histórico as categorias "produção associada", "autogestão" e "cultura do trabalho", 
fazendo referência a diferentes contextos históticos em que os trabalhadores tomaram para si os meios de produção. Destacamos o movimento por uma economia popular solidária que, desde o final da década de 1980, com a crise estrutural do emprego, se constrói em âmbito latino-americano. $\mathrm{Na}$ última parte, à guisa de conclusão e em busca de fundamentos de uma "pedagogia da produção associada", sugerimos cinco eixos de investigação que nos permitem captar as dimensões educativas do trabalho associado nas práticas de formação em economia popular solidária.

\section{Trabalho, capital e dimensão educativa do trabalho associado}

Em seu sentido genérico, o trabalho é a forma pela qual, nos processos de criação e recriação da realidade humano-social, se dá a mediação dos seres humanos com a natureza e consigo mesmos. Como parte integrante da natureza, no processo de trabalho, os seres humanos modificam sua própria natureza, construindo cultura, maneiras de fazer e pensar o mundo natural e social. As diferentes formas de construir e interpretar a realidade não são autônomas, mas construídas historicamente pelos grupos e classes sociais, consideradas, entre outras, as questões de gênero, taça, etnia e as diferenças geracionais. A organização do processo de trabalho diz respeito aos modos como, em diferentes espaços e tempos históricos, se dá a objetivação do trabalho em valores de uso de qualquer espécie. $\mathrm{Na}$ análise das diversas formas como, ao longo da história, são estruturadas e conformadas as condições materiais e imateriais da produção de bens e serviços, há de se considerar o objeto sobre o qual se trabalha (matéria bruta ou matériaprima); a disposição das máquinas e equipamentos, as condições físicas do local do trabalho (meios de trabalho) e as formas de dispêndio da força de trabalho para transformação do mundo natural em coisas úteis para os seres humanos. Se, no processo de trabalho, as forças produtivas entram em ação para materializar a atividade laboral, isto pressupõe um conjunto de conhecimentos, métodos e técnicas de produção e de gestão da força de trabalho. No entanto, vale ressaltar que:

Apenas enfocando o trabalho na sua particularidade histórica, nas mediações específicas que lhe dão forma e sentido no tempo e no espaço, podemos apreendê-lo ou apreender o mundo do trabalho na 
sua historicidade, seja como atividade criadora, que anima e enobrece o homem, seja como atividade histótica, que pode ser aviltante, penosa ou que aliena o ser humano de si mesmo, dos outros e dos produtos de seu trabalho na forma de mercadoria. (CIAVATTA, 2007, p. 43).

Por ser o processo de trabalho, em si mesmo, uma instância de produção de conhecimentos sobre o mundo natural e social, o objetivo da educação não poderia ser outro a não ser o de contribuir para que homens e mulheres trabalhadores pudessem rearticular os saberes sobre a vida em sociedade, apropriando-se do processo de trabalho em sua totalidade. $E$ também para que pudessem expressar, por meio de diversas linguagens, nossa subjetividade - objetivada pelas condições materiais e imateriais que nos constituem como seres sociais. No entanto, ao longo da história do capitalismo, aos trabalhadores tem sido negado o acesso aos instrumentos teórico-metodológicos que lhes permitam compreender os fundamentos econômico-filosóficos do mundo do trabalho. Isto porque a organização do processo de trabalho está diretamente relacionada à questão da propriedade e da posse dos meios de produção. Assim, no sistema do capital, a propriedade privada confere ao capitalista o "direito" de comprar força de trabalho e estabelecer um plano de trabalho para que os trabalhadores coletivos possam produzir com o máximo de produtividade possível. $O$ desenvolvimento tecnológico e, com ele, a divisão técnica do trabalho tornam-se elementoschave para garantir a intensificação do ritmo da produção e, por conseguinte, a subsunção real do trabalho ao capital. Embora o processo do trabalho seja em si educativo, no capitalismo, ao se configurar como trabalho alienado, tem contribuído para a desarticulação e desapropriação dos saberes da experiência e, por conseguinte, para a desqualificação do trabalhador. Sem dúvida, as atuais tecnologias de produção e gestão da força de trabalho, de base toyotista, requerem uma nova qualificação para o trabalho, no entanto a ciência permanece como segredo de poucos.

Os projetos de formação de trabalhadores caminham de mãos dadas com um determinado projeto societário. No atual contexto histórico, em que o regime de acumulação flexível dispensa uma grande quantidade de trabalho vivo, três diferentes perspectivas político-pedagógicas, de caráter mistificador, apresentam-se sob a ótica do capital: 
- educação para a empregabilidade, calcada no desenvolvimento de competências (para tornar vendável a força de trabalho no mercado capitalista);

- educação para o empreendedorismo (para estimular a "gestão do próprio negócio" e/ou tornar-se patrão de si mesmo); e

- educação para o (falso) cooperativismo (para garantir a flexibilização das relações entre capital e trabalho).

Em todas elas, a teoria do capital humano é ressignificada; a educação é considerada (e mercantilizada) como "galinha dos ovos de ouro", ou seja, o meio pelo qual o indivíduo isolado poderá usufruir os benefícios da "sociedade do conhecimento" e do "mundo globalizado". Diante da nova sociabilidade do capital, projetos educativos estão em disputa: como contraponto a qualquer perspectiva de formação do cidadão produtivo, reivindica-se uma escola unitária que, no horizonte da emancipação humana, propicie uma educação integral à classe trabalhadora. Ao invés de uma formação instrumental e "imediatamente interessada" para atender às demandas do mercado de trabalho, a escola unitária de Gramsci pressupõe uma formação humanista, de cultura geral, para todos. Para ele,

[...] a tendência democrática não pode significar apenas que um operátio manual se torne qualificado, mas que cada "cidadão" possa tornar-se governante e que a sociedade o ponha, ainda que abstratamente, nas condições gerais de fazê-lo: a democracia política tende a fazer coincidir governantes e governados (no sentido de governo com o consentimento dos governados), assegurando a cada governado o aprendizado gratuito das capacidades e da preparação técnica geral necessária a esta finalidade. (GRAMSCI, 1982, p. 137).

É ainda Gramsci (1982, p. 8) quem nos indica que, “[...] no mundo moderno, a educação técnica, estreitamente ligada ao trabalho industrial, mesmo o mais primitivo e desqualificado, deve constituir a base do novo tipo de intelectual". Assim, para além da escola, há de se buscar, no interior 
mesmo do processo de trabalho (no mais complexo e em suas formas ou modalidades mais simples), os elementos que favoreçam a formação integral do trabalhador. Se, como o filósofo italiano, tomamos como centralidade a natureza ou o caráter educativo do trabalho, os processos de formação de trabalhadores pressupõem a apreensão dos fazeres e saberes do trabalho que se tecem na cotidianidade do processo de produção (propriamente dito), tanto nas empresas sob a direção do capital como nas organizações econômicas de iniciativa popular, seja em busca da sobrevivência imediata, seja em busca de fortalecer uma "outra economia". 2 No segundo caso, não podemos esquecer que, em diversos momentos históricos, os trabalhadores têm se tornado atores protagonistas dos processos de produção da vida social, ensaiando uma cultura do trabalho calcada numa racionalidade econômico-social distinta da lógica do capital.

Sendo a práxis uma atividade humana em que ação/pensamento/ ação se apresentam como momentos indissociáveis, é ela que permite aos trabalhadores, ainda que contraditoriamente, a (re)construção da realidade humano-social. Pela práxis, o conjunto ou uma pequena parcela da classe trabalhadora tem enfrentado o desafio de produzir "por conta própria" (quer dizer, de forma autônoma) outra forma de estar no mundo. Em maior ou menor grau, "pulando o muro da fábrica" para intervir em outras instâncias das relações sociais ou circunscritos às "quatro paredes" da unidade econômica, esses trabalhadores (e trabalhadoras) têm buscado uma organização do trabalho fundada na propriedade coletiva dos meios de produção. Se a força de trabalho não é necessariamente uma mercadoria e se, tampouco, a reprodução social da vida se circunscreve às regras das relações capitalistas de produção, um dos desafios da educação é a qualificação para o trabalho emancipado, bem como o estímulo de experiências autônomas e autogestionárias, sob o controle dos trabalhadores.

Quais as dimensões educativas do trabalho associado? Embora não eliminem a alienação do trabalho que caracteriza a sociedade capitalista, a propriedade e a posse dos meios de produção trazem para os trabalhadores a possibilidade de articular os saberes que a organização capitalista do trabalho fragmentou. Assim, entendemos os processos educativos como mediação e, ao mesmo tempo, como elemento da cultura do trabalho que vai se plasmando no cotidiano da produção associada e no movimento maior de constituição de novas relações de convivência no âmbito da sociedade. 
Como Gramsci, pensamos que a educação vai além da educação escolar, invadindo todos os processos que envolvem a formação da consciência e a produção da subjetividade. Entre os diversos espaços de formação, considera que " $[. .$.$] a classe operária também se governa fora do sindicato, se governa$ no seio da fábrica de acordo com o seu local de trabalho" (GRAMSCI, 1976, p. 83). Referindo-se ao movimento grevista em Turim, entre 1919 e 1922, nos alerta para o fato de que a tarefa dos conselhos operários é fazer um estudo minucioso do sistema de produção, realizado em cada uma das sessões, buscando um ponto ótimo de produtividade e relações de trabalho. Além de gestores técnicos, os trabalhadores tornar-se-iam gestores políticos do processo produtivo, limitando o poder do capitalista na fábrica. Gramsci sugetia: "[...] por que não ctiar, na fábrica, oficinas especializadas na instrução, escapando ao embrutecimento e à fadiga, abrir seu espírito ao conhecimento dos diversos processos de produção e aperfeiçoando-se?" (GRAMSCI, 1976, p. 46).

Para Gramsci, como organismos de democracia operária, os comitês de fábrica seriam "[...] um órgão idôneo de educação recíproca" (GRAMSCI, 1976, p. 83), seriam instâncias em que se promoveria “[...] uma energia e uma vida nova", capazes de, no futuro, substituir "[...] os capitalistas em todas as funções úteis de direção" (GRAMSCI, 1976, p. 11). Embora reconheça, posteriormente, que a estratégia dos conselhos de Turim não poderia obter êxito sem a incorporação de outros setores da sociedade no processo de transformação social, Gramsci acredita que, " $[$...] como centros de vida proletária", os conselhos representam "[...] uma escola maravilhosa de experiência política e administrativa" (GRAMSCI, 1976, p. 36). Para ele, o homem, "[...] trabalhando utilmente, produzindo desinteressadamente a riqueza social, afirma a soberania, exerce seu poder e sua liberdade criadora" (GRAMSCI, 1976, p. 43).

Fundamentadas no pensamento de Gramsci quanto à dimensão educativa do trabalho e, em especial, daqueles processos que ocorrem sob o controle dos próprios trabalhadores, nossas pesquisas indicam que, ao se tornarem proprietários dos meios de produção, os trabalhadores criam - ainda que de forma contraditória - relações de mercado e de convivência distintas da lógica capitalista (TIRIBA, 1994, 2001, 2006; TIRIBA; PICANÇO, 2004). Mas, em última instância, o que nos autoriza a denominar esta ou aquela experiência associativa de "autogestionária"? Com 
que critérios é possível inferir em que medida as experiências históricas em que os trabalhadores se apropriam dos meios de produção se constituem como embrião de uma nova cultura do trabalho? Quais os significados da produção associada no interior da sociedade capitalista? Na verdade, estas e outras questões de pesquisa só podem ser respondidas se considerada a historicidade dos diversos contextos em que os trabalhadores se apropriam ou tomam posse dos meios de produção. Como sugeriu Marx (1980, p. 208, “[...] o sabor do pão não nos revela quem plantou o trigo, e o processo examinado nada nos diz sobre as condições em que ele se realiza, se sob o látego do feitor de escravos ou sob o olhar ansioso do capitalista".

\section{Crise do trabalho assalariado, economia popular solidária e educação}

A construção da autonomia do trabalho sobre o capital nos remete às origens do cooperativismo, o qual surge no início da Revolução Industrial como forma de resistência ao modo de produção capitalista. Também está relacionada a processos revolucionátios como a Comuna de Paris (em 1871) e a outras experiências históticas de trabalho associativo e autogestionário como, por exemplo, a dos falanstérios ${ }^{3}$, desenvolvidas na França e também no Brasil (inspiradas em Charles Fourier), e às Aldeias Cooperativas desenvolvidas por Robert Owen, na Inglaterra. No século $\mathrm{XX}$, tivemos, entre outras, controle operário e os sovietes de representantes operários, camponeses e soldados na Rússia (1905 e 1917), a Guerra Civil Espanhola (1936-1939), as experiências de autogestão na Iugoslávia (1950), os conselhos operários surgidos na Hungria (1956) e na Polônia (1956, 1970) com o movimento Solidarnosc (1980), a Argélia (1962) e a Revolução dos Cravos em Portugal (1974). Na América Latina e no Caribe, podem ser indicadas, entre outras, as Revoluções Cubana (1959) e Nicaragüense (1979), algumas curtas experiências vividas na Bolivia, no Peru e no Chile (1972), e a dos indígenas em Chiapas (desde 1994). ${ }^{4}$

Com a crise estrutural do emprego, não tendo intenções de revolucionar o mundo do trabalho e subverter as telações capitalistas de produção, os trabalhadores associam-se na produção tendo como objetivo a reprodução ampliada da vida (e não a reprodução ampliada do capital). Não tomando, necessariamente, para si o desafio de confrontar-se com 
o mercado capitalista, mas convivendo com ele e the sendo funcional, as organizações econômicas associativas podem estar diretamente relacionadas às questôes imediatas de sobrevivência, constituindo-se como uma estratégia de vida diante da crise do trabalho assalariado. Nunca é demais lembrar que, no contexto neoliberal, as associações cooperativas também se apresentam como um dos mecanismos utilizados pelo capital para responder às exigências do padrão de acumulação flexivel: com a contratação de cooperativas para compor a cadeia produtiva da organização toyotista do trabalho, diminuem-se custos da produção, isentando os empresários do pagamento dos direitos trabalhistas (TAVARES, 2004).

Com o processo de mundialização do capital, o esgotamento do regime fordista de acumulação e do modo de regulação social assegurado pelo Estado do Bem-Estar repercutiu em mudanças profundas na vida da classe trabalhadora. Com o preceito neoliberal de flexibilização das relações entre capital e trabalho, o trabalho assalariado com direitos sociais assegurados por vínculo empregatício dá lugar ao trabalho precátio, seja na forma de oferta de empregos com baixa remuneração, seja na forma de subcontratação, trabalho temporário ou em tempo parcial. O medo de não conseguir uma ocupação no mercado de trabalho, de perder o emprego e não ter como contribuir para o sustento da unidade familiar se tornou um verdadeiro tormento na vida das pessoas, afligindo não apenas, mas principalmente, as populações dos paises periféricos do sistema capitalista. O desemprego prolongado e a perda de direitos sociais como educação, saúde e previdência social têrn contribuído para deterioração das condições de vida, levando crianças, jovens, adultos e, também, idosos a criarem suas próprias estratégias de trabalho e de sobrevivência individuais e associativas, sejam elas lícitas, sejam ilícitas. Principalmente nos grandes centros urbanos, o binômio exclusão/inclusão, inerente ao sistema capitalista, manifesta-se com a explosão do desemprego e com a inserção dos trabalhadores em trabalhos precários: para tentar garantir a reprodução da vida (ao menos a vida biológica), apinham-se nas calçadas, numa espécie de "mercado a céu aberto". Proliferam as formas não assalariadas de trabalho, as quais, em geral, fazem parte do universo da chamada economia informal. Outra forma de "fugir" do desemprego é trabalhar associativamente, inserindo-se no que hoje se denomina economia solidária ou economia popular solidária. ${ }^{5}$ Trata-se de um conjunto de atividades econômicas e práticas sociais, nas 
quais as pessoas se associam e cooperam reciprocamente. Contrapondose à lógica da competição prôpria das organizações capitalistas, ao invés da apropriação privada, o objetivo é a apropriação coletiva dos meios de produção e, por conseguinte, dos frutos do trabalho.

Se os conceitos são construções históricas, por que não incluir no tol das experiências associativas e autogestionárias aquelas unidades produtivas e redes associativas que são parte integrante do movimento por uma economia popular solidária que, desde o final da década de 1980, se constitui em âmbito latino-americano? Partimos de análise de que, no contexto da crise estrutural do emprego, este movimento surge como uma resposta dos trabalhadores à crise social provocada pela mudança do regime de acumulação capitalista, o qual repercutiu na crise do trabalho assalariado e na perda dos direitos sociais historicamente conquistados pela classe trabalhadora. Aqueles que perderam seus postos de trabalho assalariado ocupam fábricas fechadas e, por meio de uma organização coletiva e autogestionária, assumem o controle da produção. Como comenta Naomi Klein, comparando com o movimento luddista (na Inglaterra, início do século XIX), ao invés de destruítem as máquinas para combater a lógica destrutiva do capital, os trabalhadores " $[. .$. querem proteger as máquinas e destruir a lógica” (MAGNANI, 2003, p. 15). Dado que os empresários abandonam a fábrica, ao invés de "tomar", os trabalhadores querem "tetomat" os meios de produção.

No movimento da economia popular solidária, comunidades urbanas e rurais se organizaram coletivamente como grupos de produção, compras coletivas e fundos solidários e rotativos de crédito. Também é grande a participação de populações de catadores de lixo (nos lixões e nas cidades), os quais organizaram associações e cooperativas de coleta e reciclagem. Por sua vez, pata se contrapor à subordinação à agroindústria capitalista, assentados da reforma agrária e agricultores familiates organizaram cooperativas de crédito, de produção e de serviços.

$\mathrm{Na}$ verdade, trata-se de um movimento social no qual convivem grupos sociais com diferentes concepções e projetos societários, cujas demandas são, em parte, atendidas pelo Estado e mediadas por instituições que dão apoio e assessoria para buscar assegurar a existência e a viabilidade dos chamados empreendimentos econômicos solidários. Os projetos de formação de trabalhadores associados têm sido objeto de ação de sindicatos, organizações não governamentais, igrejas, associações de moradores, 
incubadoras universitárias e das próprias organizações econômicas. Vale destacar que, no governo Lula, a incorporação da economia solidária nas políticas públicas de educação e qualificação profissional tem se dado por meio de parcerias da Secretaria Nacional de Economia Solidária (SENAESMTE) com diversos Ministérios. Para Paul Singer, secretário nacional de Economia Solidária (SENAES-MTE), "[...] a Economia Solidária é um ato pedagógico em si mesmo, na medida em que propõe nova prática social e um entendimento novo desta prática"' (SINGER, 2005, p. 19). Levando em conta os valores fundamentais que remetem à história de resistência dos trabalhadores ao capitalismo, para ele, a formação em economia solidária representa uma reeducação coletiva, ou seja, "[...] de todos os que efetuam em conjunto a transição do modo competitivo ao cooperativo de produção" (SINGER, 2005, p. 19).

A compreensão das dimensões educativas do trabalho associado há de ter como referência as experiências de formação de trabalhadores associados e de formação de formadores, a análise da produção acadêmica e dos materiais pedagógicos (em getal, produzidos pelas organizações de apoio à economia solidária). Podemos dizer que, no seio da economia solidária, de uma maneira geral, se destacam as seguintes concepções teórico-metodológicas:

- enfatizam-se os aspectos éticos das relações sociais, em especial, a cooperação e a solidariedade (educação humanista);

- busca-se, no resgate da cultura popular e nos pressupostos da educação popular, a possibilidade de uma práxis libertadora e emancipadora; (educação emancipadora);

- considera-se o trabalho como instância e princípio educativo; ênfase na necessidade de superação da sociedade capitalista (educação integral).

A diversidade de práticas educativas no movimento por uma economia (popular) solidária expressa, de alguma maneira, as compreensões diferenciadas que se têm sobre os significados do trabalho associado para fazer frente ao desemprego estrutural e à precarização do trabalho, que caracterizam o capitalismo no regime de acumulação flexível. Essas práticas estão relacionadas às idéias de educação cooperativa, educação autogestionária, incubação de cooperativas ou de empreendimentos 
econômicos solidários, formação/educação em economia solidária, pedagogia autogestionária e pedagogia da produção associada. De acordo com o documento que resultou da I Oficina Nacional de Formação/ Educação em Economia Solidária, realizada pela SENAES e pelo Fórum Brasileiro de Economia Solidária (FBES), em dezembro de 2005, na qual estiveram presentes 40 representantes de 22 Estados (incluindo experiências de âmbito nacional), a formação de trabalhadores associados segue os mesmos princípios da economia solidária.

[...] ao mesmo tempo em que se substancia na denúncia da exploração do trabalho, na critica à lógica excludente da economia capitalista e ao sistema opressor que fragmenta o ser humano (dividindo a sociedade entre "compradores e vendedores de força de trabalho"), os processos educativos inspirados na Economia Solidăria anunciam uma nova sociabilidade, uma nova sociedade, uma nova forma de produção da vida. [...] Como nos demais processos autogestionários de produção da vida, a educação/ formação tem como perspectiva o trabalho-criação, no qual homens e mulheres têm o controle sobre todo o processo (produção, administração, beneficiamento, distribuição, troca e consumo ético/ crítico/consciente dos frutos do seu trabalho). (MINISTÉRIO DO TRABALHO E EMPREGO, 2006, p. 15).

O que significa dizer que a economia (popular) solidária se constrói com vistas a fomentar e dar organicidade às praticas econômicas associativas fundadas na propriedade coletiva dos meios de produção e numa cultura do trabalho inspirada nos princípios da autogestão? No contexto de uma nova totalidade social, as categorias "produção associada", "autogestão" e "cultura do trabalho" são ressignificadas, ganhando nova concretude histórica.

\section{As categorias e suas mediações históricas}

Entendemos que os conceitos são categorias "grávidas de história". De acordo com o materialismo histórico, 
[...] até as categorias mais abstratas - precisamente por causa de sua natureza abstrata -, apesar de sua validade para todas as épocas, são, contudo, na determinidade desta abstração, igualmente produto das condiçōes históricas, e não possuem plena validez senão para estas condições e dentro dos limites destas. (MARX, 1978, p. 120).

Neste sentido, para compreender as dimensões educativas dos processos de trabalho sob o controle dos trabalhadores, acreditamos ser necessário historicizar, entre outras, as categorias "produção associada", "autogestão" e "cultura do trabalho" - categorias estas que, no horizonte da emancipação da classe trabalhadora, se relacionam e se articulam.

A categoria "produção associada" está relacionada a associativismo, entendido como um conjunto de práticas sociais informais ou instituídas desenvolvidas por grupos que se organizam em torno dos ideais e objetivos que compartilham. Podendo ser de abrangência local, regional, nacional ou internacional, o associativismo caracteriza-se pela construção de laços sociais calcados na confiança, cooperação e reciprocidade, o que confere aos seus membros o sentimento de pertencimento ao grupo. Quanto à produção associada, ela pode ser entendida de duas maneiras, não necessariamente excludentes: quer como trabalho associativo ou processo em que os trabalhadores se associam na produção de bens e serviços, quer como a unidade econômica básica da "sociedade dos produtores livres associados". No horizonte da emancipação humana e da superação da sociedade capitalista, para Karl Marx, o modo de produção de produtores associados seria fundado na propriedade coletiva dos meios de produção, na gestão coletiva do processo e na socialização dos frutos do trabalho. Embora não tenha tratado de formas particulares de associação cooperativa, considera que, a despeito de ser limitada na sociedade de classes, a produção associada pode representar a célula deste novo modo de produção. Marx declara, em 1864, na ocasião da criação da Associação Internacional de Trabalhadores, que "[...] o trabalho associado, que maneja suas ferramentas com a mão hábil e entusiasmada, espírito alerta e coração alegre", representa a negação do trabalho assalariado. Para ele, "[...] estas fábricas demonstram como, ao chegar a uma determinada fase de desenvolvimento das forças materiais produzidas e das formas sociais de produção adequadas a elas, do 
seio de um regime de produção surge e se desenvolve naturalmente outro novo" (MARX apud BOTTOMORE, 1993, p. 20). No entanto, alerta que a derrota do capitalismo só será possível com o poder político nas mãos da classe trabalhadora e que, enquanto as associações cooperativas não se desenvolveram em nível nacional, representam apenas "[...] um estreito círculo dos esforços casuais de grupos de trabalhadores" (MARX apud BOTTOMORE, 1993, p. 20).

A produção associada pode ganhar vários sentidos. Resguardadas suas particularidades históricas, no caso da Guerra Civil Espanhola (1936-1939) e do movimento popular posterior ao 25 de Abril de 1974 (em Portugal), por exemplo, é merecedora de aprofundamento empírico e teórico a questão da produção associada como forma de associatividade, de controle operário sobre a produção e, também, de controle sobre o próprio processo revolucionário. No que diz respeito à situação da Nicarágua, depois do periodo revolucionário sandinista, Núñez Soto (1998) acredita que, assim como os empresários tiveram que se associar para que as relações de produção capitalistas se tornassem hegemônicas, também os trabalhadores precisam se organizar em torno da "[...] economia popular associativa e autogestionária". No El manifiesto asociativo y autogestionario, Núñez Soto (1998) propõe o fortalecimento de um bloco social composto por movimentos sociais, famílias, comunidades locais e associações autogestionárias de produtores e que se construa um sistema comunitário que potencialize relações de cooperação e solidariedade.

O conceito de produção associada não está, necessariamente, relacionado com a perspectiva de transformação das relações capitalistas de produção. Ele pode ter a conotação de trabalho associativo ou processo em que os trabalhadores se associam na produção de bens e serviços. Isto pode ser verificado no atual momento da acumulação flexível, em que a crise estrutural do emprego repercute na proliferação das estratégias associativas de trabalho, entre elas as associações cooperativas. Como afirma Antunes (1999, p. 14), na nova reestruturação produtiva, "[...] enquanto na fábrica fordista aproximadamente $75 \%$ da produção era realizada no seu interior, a fábrica toyotista é responsável por somente $25 \%$ da produção, tendência que vem se intensificando ainda mais". Isto significa que, para os empresários e seus representantes, as organizações econômicas dos trabalhadores associados podem se tornar "um negócio da China". Embora 
não tenham perspectiva de se contrapor à economia capitalista, estas estratégias pressupõem a propriedade e/ou posse dos meios de produção e o controle do processo de trabalho pelos trabalhadores. Assim, no Brasil, para diferenciar as associações cooperativas e outras formas de produção associada que pretendem se opor à lógica capitalista, tem-se utilizado os termos "cooperativismo popular" e "cooperativismo autogestionário".

E quanto à categoria "autogestão"? Que diferentes conotações ganha ao longo da história? Como Bruno (1990, p. 37), pensamos que as "[...] práticas autogestionárias têm que realizar uma alteração profunda nas relações de trabalho, destruindo os processos de valorização do capital". Assim, embora o termo seja, atualmente, utilizado pelos empresários, não se confundem com autogestão as práticas capitalistas de organização de equipes de trabalhadores em "grupos autônomos", "semi-autônomos", "ilhas de produção", e outras tecnologias toyotistas de produção e gestão da fotça de trabalho. No sentido político, econômico e filosófico, autogestão é um conceito que encerra a idéia de uma forma de organização social em que os sujeitos têm autonomia e autodeterminação na gestão do trabalho e em todas as instâncias das relações sociais. Tem como pressupostos a propriedade comum e a posse dos meios de produção da vida social e, por conseguinte, o controle coletivo e soberano das relações que os grupos sociais estabelecem com a natureza e entre si no processo de produção da existência humana. Nessa acepção, a autogestão tem o ideário da superação das relações de produção capitalistas e a constituição do socialismo, concebido como uma sociedade autogestionária. No sentido restrito, é uma atividade econômica caracterizada pela propriedade coletiva dos meios de produção de bens e serviços e pela participação ativa dos trabalhadores nas decisões da organização.

Por que é preciso historicizar a categoria “autogestão"? Porque, assim como ocorreu no movimento popular pós-25 de Abril (Portugal, 1974), por exemplo, muitas têm sido, atualmente, as experiências de "controle operátio". Embora não se trate de um "movimento revolucionátio", em meados da década de 1980 e início dos anos 1990, em âmbito latino-americano, várias indústrias passaram a ser denominadas "autogestionárias". Em geral, este tipo de "controle operário sobre a produção" tem se instalado em fábricas abandonadas pelos patrões, nas quais a autogestão pode ser entendida, apenas, como um método de gestão. No Brasil, no contexto da crise 
estrutural do emprego, as primeiras experiências ocorreram na Companhia Carbonifera do Araranguá (CBCA) (hoje, COOPERMINAS, em Santa Catarina), Wallig-COOMEC (Rio Grande do Sul); Cobertores Paraíba e Markely Calçados (São Paulo), Caraíba Mineração (Bahia), Remington Indústria de Máquinas de Escrever (Rio de Janeiro), entre outras. Em 1993, o Sindicato dos Mineiros de Criciúma/Santa Catarina sediou o I Seminário Nacional de Autogestão; em 1994, foi criada a Associação Nacional de Trabalhadores de Empresas de Autogestão (ANTEAG). Atualmente, entre tantos outros, são exemplos a UNIFORJA (São Paulo), a CIPLA (em Santa Catarina) e a Catende-Harmonia (Pernambuco). Esta última foi criada em 1995, na Zona da Mata, resultado da Iuta organizada dos trabalhadores para evitar o fechamento e a perda do patrimônio da Usina Catende. Envolvendo 12 mil familias, a Catende é considerada uma das mais importantes experiências no campo.

A guisa de uma espécie de flashback, o movimento por uma economia (popular) solidária cresceu a partir do ano 2000, sob a coordenação do Fórum Brasileiro de Economia Solidária - FBES. No plano das políticas públicas, em nível estadual, havia sido criado no Rio Grande do Sul, durante o governo de Olívio Dutra (1999-2002), um programa de estímulo a essa "outra economia". Em julho de 2003, no primeiro governo de Luiz Inácio Lula da Silva, foi criada, no âmbito do Ministério do Trabalho e Emprego, a Secretaria Nacional de Economia Solidária (SENAES), buscando fortalecer as atividades econômicas organizadas coletivamente pelos trabalhadores que se associam e se orientam pelos princípios da autogestão. Simultaneamente, como resposta dos trabalhadores à crise estrutural do capitalismo, os trabalhadores associados construíram na Argentina e no Uruguai o movimento das Fábricas Ocupadas e Empresas Recuperadas. $\mathrm{Na}$ Venezuela, criou-se em 2006 o Ministério da Economia Popular com o objetivo de criação de cooperativas para fazer frente às empresas consideradas improdutivas e, ao mesmo tempo, fortalecer a perspectiva de uma economia endógena. Para Santos (2002), crescem, atualmente, as redes associativas em âmbito internacional, envolvendo unidades econômicas, complexos cooperativos e movimentos sociais em torno da lógica de "produzir para viver". Em síntese, podemos afirmar que, no atual contexto histórico em que os trabalhadores se vêem obrigados a criar estratégias associativas de trabalho, a autogestão se tornou uma "palavra de 
ordem" do movimento por uma economia (popular) solidária e em outros movimentos de trabalhadores associados na produção.

"Cultura do trabalho" é a terceira e última categoria de conteúdo que elegemos para inferir sobre as dimensões educativas dos processos de trabalho sob o controle dos trabalhadores. Sendo mediada por processos educativos, é ela que nos permite a análise das relações entre trabalho e educação no chão da fábrica. Cultura do trabalho diz tespeito aos elementos materiais (instrumentos, métodos, técnicas, etc.) e simbólicos (atitudes, idéias, crenças, hábitos, representações, costumes, saberes) partilhados pelos grupos humanos - considerados em suas especificidades de classe, gênero, etnia, religiosidade e geração. Determinada em última instância pelas relações de produção, nos remete a objetivos e formas sobre o dispêndio da força de trabalho, maneiras de pensar, sentir e se relacionar com o trabalho. Os grupos humanos trabalham de acordo com uma determinada cultura $e$, ao trabalharem, produzem cultura; assim, como salienta Marx (1978, p. 110), "[...] a produção não só cria um objeto para o sujeito, mas também um sujeito para o objeto". Sendo a síntese de múltiplas determinações, na cultura do trabalho há de se considerar, entre outras, as diferenças de classe, gênero e etnia. Está relacionada com o papel dos sistemas simbólicos na vida social e, em especial, dos valores morais atribuidos à atividade do trabalho, sendo construida e interiorizada em outras instâncias de convivência, entre elas, familia, escola, igreja, sindicato e outras instituiçöes que modulam modos de vida e relações entre grupos e classes sociais. Podemos dizer que, no Brasil, diversas culturas do trabalho sobrevivem, convivem e/ou se tornam subordinadas à cultura capitalista, entre elas destacam-se as dos quilombolas, caiçaras e indígenas. Sem dúvida, a cultura do trabalho que se constrói na economia (popular) solidária também está subordinada aos processos de valorização do capital, sendo dependente da lógica do mercado.

A análise da dimensão educativa do trabalho associado requer a reconstrução histórica da totalidade social do espaço/tempo em que os sujeitos estão imersos (o que, em última instância, requer pesquisa). $\mathrm{Na}$ Remington, indústria de máquinas de escrever, no Rio de Janeiro, que viveu um processo autogestionário entre 1990 e 1994, é possivel perceber que, como forma de resistência ao trabalho, mesmo depois de os trabalhadores se tornarem proprietários dos meios de produção, persistia a cultura da "meia-máquina", ou seja, persistia a "cera". Isto significava que, num 
contexto em que a força de trabalho deixou de ser consumida/explorada pelos empresários, a propriedade coletiva parecia conferir aos trabalhadores uma espécie de "direito ao não-trabalho", ou seja, de gozar o "direito à preguiça” - sonhado por Paul Lafargue (TIRIBA, 2006a). No caso da Guerra Civil Espanhola, ocorrida entre 1936 e 1939, é possivel constatar a dicotomia entre projeto educativo (cujo horizonte era a formação omnilateral dos trabalhadores) e organização do processo de trabalho (inspirado nos princípios do taylorismo). Além disso, para que pudessem construir uma nova cultura do trabalho, compreender o mundo do trabalho e definir os rumos da produção em função da luta contra o fascismo, foi preciso enfrentar, também, a luta contra o analfabetismo (TIRIBA, 2006b).

Sobre as diferentes formas de ação e de luta pela transformação social e, em especial, sobre as dimensões educativas do movimento popular pós25 de Abril, Canário (2007) ressalta o aprendizado coletivo "[...] que marca o período de 'ouro' da educação e formação de adultos em Portugal, nas três últimas décadas" (CANÁRIO, 2007, p. 11). No contexto português, também há de se considerar na cultura do trabalho a formação multicultural ibérica, os efeitos das políticas de educação de adultos ocortidas durante o regime fascista e, além disso, a mediação dos conselhos operários, do Jornal Combate, dos mercados solidários, etc. Os estudos de Faria (2005) sobre autogestão nos indicam que, imediatamente após o levante militar e a queda do regime fascista, os empresários e militares que assumiram o governo

[...] viram-se surpreendidos por um tsuname de movimentos coletivos e ativos" [...] Greve dos padeiros, greve "contra o aumento do preço da bica", greve dos jornais em solidariedade à luta em outros jornais, greve dos camponeses [...] Mas não foi apenas na esfera da produção que as instituições se viram questionadas. Nas administrações públicas, nas escolas e liceus, na âmbito da prođução cultural, no sistema judiciário, no exército, na Igreja e na familia, processos intensos de ruptura com a herança cultural do fascismo insinuaram-se e aceleraram efetivamente a história em Portugal. E também formas de intervenção na organização da cidade, como nos casos de ocupação das habitações vacantes, na sequestração de ônibus para a mudança de rotas ou para a imposição 
de novos pontos de parada, na definição dos valores máximos dos aluguéis pelos moradores de determinadas zona etc. (FARIA, 2005, p. 227).

Para analisar os diferentes contextos históricos em que os trabalhadores tomam para si os meios de produção, são elucidativos os estudos de Thompson (1997) sobre a cultura dos trabalhadores nos séculos XVIII e XIX. O historiador afirma que a classe social é uma formação tanto cultural como econômica, pois são as experiências comuns (herdadas ou partilhadas) que criam uma identidade de interesses que diferem (e geralmente se opõem) da de outros homens Acredita que, em grande medida, as experiências são determinadas pelas relações de produção; no entanto, "[...] a consciência de classe é a forma como essas experiências são tratadas em termos culturais: encarnadas em tradições, sistemas de valores, idéias e formas institucionais" (THOMPSON, 1997, p. 10).

\section{Por uma pedagogia da produção associada (ou à guisa de conclusão)}

Como estratégia de sobrevivência e/ou de construção de novas relações de produção no âmbito de toda sociedade, o trabalho associado pressupõe a propriedade ou a posse dos meios de produção, a divisão igualitária do excedente de trabalho e a instalação de mecanismos de decisão coletiva no interior da unidade produtiva. As experiências históricas de produção associada nos fazem enveredar por espaços e tempos com raízes econômicas, políticas, sociais e culturais distintas. No entanto, o que elas têm em comum são as contradições entre capital e trabalho. Sendo a educação uma prática social mediadora e, ao mesmo tempo, elemento da cultura do trabalho que se plasma no cotidiano das relações que os trabalhadores associados estabelecem com a natureza, entre si e com a sociedade, tornase necessário buscar suas particularidades históricas. Como nos elucida Ciavatta (2001, p. 141),

Do ponto de vista metodológico, a categoria da particularidade vai nos permitir retirar a relação trabalho $\mathrm{e}$ educação da sua generalidade e apreendê-la, enquanto mediação privilegiada de um processo em curso na sociedade, nas diversas conjunturas histórico-sociais. 
Em outros termos, retirá-la de sua abstratividade lógica, genérica e buscar as formas sociais concretas de sua realização histórica.

Para analisar as dimensões educativas do trabalho associado, um dos desafios é entender o fenômeno tendo em conta a totalidade históricosocial na qual se dá, hoje, um "novo" tratamento à "questão social". Em outras palavras, há de se considerar as contradições da produção associada no interior da sociedade capitalista e, em especial, o papel que jogam as organizações econômicas associativas no contexto da reestruturação produtiva, necessária à acumulação flexível. Como sugere Novaes (2006, p. 16),

[...] o problema é que, mesmo as cooperativas que surgiram por iniciativa dos trabalhadores compromissados com a luta pela transformação substantiva da sociedade estão sendo funcionais a esta nova fase do capitalismo mundial, caracterizada pela perda significativa de direitos trabalhistas e barbárie social.

Não podemos deixar de considerar a reconstituição das bases de hegemonia do capital na sociedade contemporânea, as ambigüidades do governo Lula quanto às contradições entre capital e trabalho, bem como as políticas públicas que estimulam atividades econômicas não assalariadas para os trabalhadores desempregados. Ao analisar a economia solidária como política pública, Barbosa (2007) adverte que não existe uma autonomia da economia solidária em relação à lógica capitalista e que tampouco ela é "[...] potencialmente redentora e capaz de levar à libertação do capital, além de promover o aumento da democracia" (BARBOSA, 2007, p. 26). Além disso, vale não esquecer que o movimento por uma economia (popular) solidária é um campo de disputa, do qual participam e estão em confronto diferentes projetos societários.

Entendemos que as experiências de trabalho associado podem se constituir como uma "escola" de produção de uma cultura do trabalho que, inspirada nos princípios da autogestão, se contraponha à lógica do sistema capitalista. Também é uma "escola" na qual aprendemos que, no interior do capitalismo, a produção associada é, em si, deveras limitada. E que, se temos como horizonte a "[...] sociedade dos produtores livres associados" (Marx), 
é preciso construir processos educativos coadunados com um projeto maior de transformação social. Como Gramsci (1982), pensamos que o objetivo da educação é que os trabalhadores associados possam se tornar "governantes" do seu trabalho e, além disso, sujeitos-criadores de história. Assim, pensamos ser fundamental apreender nas experiências históricas dos trabalhadores os fundamentos econômico-filosóficos de uma pedagogia que se tece na perspectiva de um projeto societário de emancipação da classe trabalhadora. No horizonte da sociedade dos produtores livres associados, denominamos "pedagogia da produção associada" o campo teórico-prático que visa ao estudo e à concretização dos processos educativos que têm como objeto de pesquisa e de ação a socialização, a produção, a mobilização e a sistematização de saberes sobre o mundo do trabalho que contribuem para a formação integral dos trabalhadores associados. Na busca de seus fundamentos nas práticas educativas da chamada economia solidária, sugerimos cinco eixos de análise.

\section{Projeto societário}

São feitas criticas à sociedade capitalista? Indica-se a existência de projetos societários em disputa? Anuncia-se a possibilidade de construção de uma nova sociedade? Qual o significado da propriedade coletiva dos meios de produção? Qual a relação entre economia solidária e projeto societário? Qual a relação entre projeto educativo e projeto societário?

\section{Economia (popular) solidária}

Qual a concepção de economia solidária? Seu objetivo é para amenizar a crise do emprego e a "dor dos pobres"? Reivindica-se o "popular" na economia? Quais os horizontes políticos, econômicos, sociais e culturais dos processos educativos? Busca-se a unidade entre objetivos econômicos e objetivos sociais? Em que medida o processo educativo persegue os princípios da economia solidária?

\section{Solidariedade}

O que se entende por solidariedade? Qual a relação entre pobreza e solidariedade? Em que medida a solidariedade se estende à comunidade 
local e à sociedade em geral? Que diferentes estilos de solidariedade são valorizados? Por que as pessoas devem ser solidárias? Qual a relação entre solidariedade e crise do Estado do Bem-Estar?

\section{Trabalho e autogestão}

O trabalho é compreendido como categoria central da formação humana e das relações sociais? O trabalho é compreendido como instância educativa? O trabalho é compreendido como princípio educativo? O que se entende por autogestão? Qual a relação entre cultura do trabalho e projeto societário? A autogestão é um princípio norteador da prática educativa? A prática educativa é, em si, autogestionária?

\section{Educação e produção de saberes}

Como é entendido o processo de produção de conhecimento? As práticas dos trabalhadores são valorizadas? O processo educativo tem como referência os saberes da experiência? Que saberes da experiência são explicitados? Os saberes acadêmicos são valorizados? Os saberes da experiência são articulados aos saberes historicamente acumulados e sistematizados? Qual a relação existente entre formação de trabalhadores e viabilidade econômica do empreendimento? Qual a diferença e como se relacionam a formação técnica e a formação política? Que peso tem a educação no processo de transformação social?

Uma cultura do trabalho de novo tipo tem como pré-requisitos a propriedade e a posse coletiva dos meios de produção, o controle sobre o processo e o produto do trabalho, e que a força de trabalho deixe de ser uma mercadoria. Para que ela se constitua na sua plenitude, é preciso também romper com o sistema capitalista. Sendo assim, na perspectiva de uma sociedade dos produtores livres associados, o sentido da educação

[...] não pode ser senão o rasgar a camisa de força da lógica incorrigivel do sistema: perseguir de modo planejado e consistente uma estratégia de rompimento com o controle exercido pelo capital, com todos os meios disponiveis, bem como com todos os meios ainda a ser inventados e que tenham o mesmo espírito. (MÉSZÁROS, 2005, p. 78). 
Configurando-se como um processo práxico-educativo de criação de novas concepções de mundo, a produção associada é uma "escola" que pode contribuir não apenas para driblar o desemprego e outras contradições entre capital e trabalho, mas para que a classe trabalhadora descubra que o capitalismo não é um sistema inexorável.

\section{Notas}

1. Referimo-nos à nossa atual pesquisa intitulada "Trabalho, educação e economia (popular) solidária: elementos para uma pedagogia da produção associada", por mim coordenada, contando com a participação de Bruna Sichi e Keila Lúcia de Carvalho, bolsistas de Iniciação Científica (FAPERJ e PIBIC/CNPq, respectivamente). Como pesquisadora externa, temos a profa. Dra. Maria Clara Fischer, do Programa de PósGraduação em Educação da UNISINOS-RS.

2. Sobre uma racionalidade econômica que se distingue da economia capitalista, ver conceitos essenciais em Cattani (2003).

3. Falanstérios são uma espécie de edifício-cidade no qual as pessoas trabalham apenas naquilo que desejam e segundo suas vocações. Os falanstérios foram inspirados na proposta utópica de Charles Fourier (1772-1837), filósofo e economista político francês, que defendeu o fim da dicotomia entre trabalho e prazer. Nos falanstério, os bens são distribuídos conforme a necessidade. A divisão das riquezas produzidas é feita considerando-se a quantidade e a qualidade do trabalho de cada um.

4. Para uma análise das lutas operárias autônomas e autogestionárias, ver: Nascimento (1986).

5. De nossa parte, reivindicar o "popular" na economia solidária significa que, por uma questão de classe, não abrimos mão de uma economia que favoreça a maioria da população planetária, que sem dúvida pertence à classe trabalhadora. $\mathrm{O}$ aprofundamento desta questão se encontra em Tiriba (2004, p. 75-102). 


\section{Referências}

ANTUNES, Ricardo. Os sentidos do trabalbo: ensaios sobre a afirmação e negação do trabalho. São Paulo: Boitempo, 1999.

BARBOSA, Rosângela. A economia solidária como política pública. São Paulo: Cortez, 2007.

BOTOMORE, Tom. Dicionário do pensamento marxista. Rio de Janeiro: Jorge Zahar, 1993.

BRUNO, Lúcia. O que é autonomia operária. São Paulo, Brasiliense, 1990.

CANÁRIO, Rui. A educação e o movimento popular do 25 de Abril. In: . (Org.). Educafão popular e movimentos sociais. Lisboa: Educa/Unidade de I e D de Ciências da Educação, 2007. p. 11-36.

CATTANI, Antonio David. A outra economia. Porto Alegre: Veraz, 2003. CIAVATTIA, Maria. O conhecimento histórico e o problema teóricometodológico das mediações. In: FRIGOTTO, G.; CIAVATTA, M. Os labirintos do capital. Petrópolis: Vozes, 2001. p. 121-144.

CIAVATTA, Maria (Org.). Memória e temporalidades do trabalho e da educa̧̧ão. Rio de Janeiro: Lamparina: FAPERJ, 2007.

FARIA, Maurício Sardá. Autogestão, cooperativa, economia solidária: avatares do trabalho e do capital. 2005. Tese (Doutorado em Sociologia) - Centro de Filosofia e Ciências Humanas. Programa de Pós-Graduação em Sociologia Política, Universidade Federal de Santa Catarina, Florianópolis.

GRAMSCI, Antonio. Democracia operária, partidos, sindicatos e conselbos. Coimbra: Centelha, 1976.

Os intelectuais e a organização da cultura. Rio de Janeiro: Civilização Brasileira, 1982.

MAGNANI, Esteban. El cambio silencioso: empresas y fábricas recuperadas por los trabajadores en Argentina. Buenos Aires: Prometeo Libros, 2003.

MARX, Karl. O capital. crítica da economia política. Rio de Janeiro: Civilização Brasileira, 1980.

Introdução à crítica da economia política. In: OS PENSADO-

RES. São Paulo: Abril Cultural, 1978. 
MINISTÉRIO DO TRABALHO E EMPREGO. Secretaria de Economia Solidátia. I Oficina Nacional de Formaşão/ Educafãa em Economia Solidária. Brasilia, 2006.

NASCIMENTO, Cláudio. As lutas operárias autônomas e autogestionárias. Rio de Janeiro: CEDAC, 1986.

NOVAES, Henrique. Quando os patrões destroem fábricas: o debate em torno das forças produtivas em fábricas recuperadas argentinas e uruguaias. Trabalbo Necessário, Fluminense, RJ, n. 4, p. 1-20, 2006.

NÚÑEZ SOTO, Orlando. El manifiesto asociativo y autogestionaário. Managua: CIPRES, 1998.

MÉSZÁROS, István. A educafão para além do capital. São Paulo: Boitempo, 2005.

SANTOS, Boaventura de Souza (Org.). Produgir para viver. os caminhos da produção não capitalista. Rio de Janeiro: Civilização Brasileira, 2002.

TAVARES, Maria. A. Os fios (in)visiveis da produção. São Paulo: Cortez, 2004.

THOMPSON, E. P. A formą̧ão da classe operária inglesa: a árvore da liberdade. Rio de Janeiro: Paz e Terra, 1997.

TIRIBA, Lia. Autogestão e chão de fábrica: um ensaio inspirado nos trabaIhadores da Remington. Fluminense, RJ: UFF, 1994. Relatório final de pesquisa.

Autogestão, disciplina no trabalho e o direito à preguiça. In: TORRES, A; SEMERARO, G.; PASSOS, L. A.(Org.). EDUCAÇÃO: fronteira política. Cuiabá: EdUFMT, 2006a. p. 71-84.

Trabalho e educação na Guerra Civil Espanhola. Revista Histebr On-Line, Campinas, 21, p.180-200, maio 2006b.

Economia popular e cultura do trabalbo: pedagogia(s) da produção associada. Ijui: Unijuí, 2001.

Ciência econômica e saber popular: reivindicar "o popular" na economia e na educação. In: TIRIBA, Lia; PICANÇO, Iracy (Org.). Trabalbo e educação: arquitetos, abelhas e outros tecelões da economia popular solidária. Aparecida, SP: Idéias e Letras, 2004. p. 75-102. 


\section{Culture of work, self mana- gement and worker educa- tion associated to production: research questions}

\begin{abstract}
:
This article is based on the supposition that concepts are products of the historic conditions of a given space and time and carry with them something that both is and that is coming to be. In search of theoretical and methodological support for an analysis of the educational dimensions of labor processes under worket control, we review the categories of "associated production", self management and labor culture from a historical materialist perspective. Different contexts are presented in which workers have taken control of the means of production. We analyze the educational processes of associated workers, based on the social movement for a popular solidarity-economy which, since the structural employment crisis of the late 1980's, has been mounting in Latin America.
\end{abstract}

Key words: Worker-Education. Labor.

\section{Lia Tiriba}

Rua Santa Cristina, 46, apto/201 - Santa Teresa

Rio de Janeiro - RJ

CEP: 20241-250

Tel: (21) 2242-0664

E-mail:liatiriba@oi.com.br
Cultura del trabajo, autogestión y formación de trabajadores asociados en la producción: cuestiones de investigación

\section{Resumen:}

Partimos del presupuesto que los conceptos son productos de las condiciones históricas de un determinado espacio/tiempo, y contienen en si mismos algo que es pero también algo que podría llegat a ser. Buscamos subsidios teórico - metodológicos que puedan contribuir para la reflexión sobre las dimensiones educativas de los procesos del trabajo, sobre el control de los trabajadores, (re)visitando - a partir del materialismo histórico - las categorías de 'producción asociada', 'autogestión' y 'cultura del trabajo', haciendo referencias a los diferentes contextos en que los trabajadores tomaron para si los medios de producción. También problematizamos los procesos de formación de los trabajadores asociados, teniendo en cuenta el movimiento social pata una economía popular solidaria que se construyó, al final de la década de 1980 con la crisis estructural del empleo en América Latina.

Palabras-clave: Trabajadores-Formación. Trabajo.

Recebido em: 6/5/2008

Aprovado em: 28/5/2008 